\title{
Product environmental assessment as vector of differentiation-ACéVOIL, a new tool for the vegetable oil sector ${ }^{\star}$
}

\author{
Laureen Badey ${ }^{*}$ and Fabrice Bosque \\ ITERG, 11 rue Gaspard Monge, Parc Industriel Bersol 2, 33610 Canejan, France
}

Received 16 October 2017 - Accepted 8 January 2018

\begin{abstract}
Environmental impacts of human activities, heightened consumer concern over the food they eat, and business survival hinging on increasing performance mean there is pressure from all sides to reduce product environmental impacts - a strategic challenge to help keep businesses in business and improve competitiveness. Conscious of this challenge, the oilcrop commodity chain wanted to provide vegetable oil producers and users with a tool for assessing the environmental impacts of vegetable oil-based foods. The tool is called ACéVOIL, and can be used to validate the environmental value benefit of ecodesign initiatives as-deployed or as-designed. ACéVOIL accounts for every stage in the end-to-end commodity production and distribution process, making it possible to control and contain any pollution transfers between two distinct environmental impacts or two lifecycle stages. The tool also outputs results that can be readily communicated out to clients and/or consumers as part of a product information backbone to differentiate from competitor products and up-value the ecodesign initiatives implemented. However, communicating LCA results out to the general public can prove tricky business, so the exercise needs to be managed with care and forethought. Several upgrades are envisioned to extend the scope of ACéVOIL out to biomass-based products made from pure or processed vegetable oils.
\end{abstract}

Keywords: vegetable oils / lifecycle assessment / environmental impact assessment / ecodesign / environmental communication

Résumé - L'évaluation environnementale des produits comme vecteur de différenciation-présentation de l'outil ACéVOIL pour le secteur des huiles végétales. Les impacts sur l'environnement des activités humaines, la préoccupation environnementale accrue des consommateurs vis-à-vis des aliments qu'ils consomment ainsi que la nécessité pour les entreprises d'augmenter leur performance, font de la réduction des impacts environnementaux des produits un enjeu stratégique pour assurer la pérennité des entreprises et améliorer leur compétitivité. Forte de ce constat, la filière oléagineuse a souhaité mettre à la disposition des producteurs et utilisateurs d'huiles végétales un outil d'évaluation des impacts environnementaux des produits alimentaires formulés à partir d'huiles végétales : l'outil ACéVOIL. L'outil peut être utilisé pour valider l'intérêt environnemental des actions d'écoconception mises en œuvre ou envisagées. Il prend en compte l'ensemble des étapes de fabrication et de distribution du produit, ce qui permet de s'affranchir d'éventuels transferts de pollution entre deux impacts environnementaux distincts ou deux étapes du cycle de vie. L'outil fournit également des résultats communicables aux clients et/ou consommateurs du produit afin, notamment, de se différencier des produits concurrents et de valoriser les actions d'écoconception mises en œuvre. Cependant, la communication des résultats d'ACV au grand public peut s'avérer délicate et doit être réalisée avec précaution. Plusieurs évolutions de l'outil sont envisagées afin d'étendre son champ d'application aux produits biosourcés fabriqués à partir huiles végétales ou de ses dérivés (the full text is available in French on http://www.ocl-journal.org/).

Mots clés : huiles végétales / analyse de cycle de vie / outil d'évaluation environnementale / écoconception / communication environnementale

\footnotetext{
„ The French version is available in "Supplementary Material".

*Correspondence: 1 .badey@iterg.com
} 


\section{Background}

The all-too-visible environmental impacts of human activity-resource depletion, habitat destruction, pollutant emissions - have reached such a point that it is imperative to factor the environment into everything we do. Food commodities, like any other sector of activity, generate environmental impacts-greenhouse gas emissions, ground and air pollution, energy- and water-resource use, etc.- - at every stage in the entire end-to-end food product lifecycle. The impacts of upstream farming are by far the biggest, and are connected to the use of land, fertilizers, herbicides and pesticides, and farm machinery. The impacts of downstream food-industry processing, which are not as big, are connected to the use of energy resources and the production of packagings for packing and portioning the foods. The big food processors nevertheless have a vital role to play in controlling and cutting the environmental footprint of food products as part of the wider effort to reduce human impact on the environment.

This environmental urgency articulates with consumer concerns. The latest surveys published on this topic all show French shoppers turning to more environmentally-friendly food products (Rolland, 2017). In 2015, one in two French shoppers had bought a food product carrying an environmental label in the previous month, against 40\% in 2009 (Pautard, 2016). When asked who needs to be first to change their behavior in order to relieve human pressure on the environment, $41 \%$ of respondents singled out business, with only $20 \%$ citing the consumer (Rolland, 2017). When asked what needs to be brought in to help guide their purchase decisions, $77 \%$ of consumers welcomed the introduction of environmental information labelling, for all categories of product and on all points of sale, with food products counting among the category for which environmental information was most in demand (Ceci-Renaud et al., 2017).

Over and above moving to help reduce the environmental footprint and improve the brand image of its product, integrating environmental sustainability performance right from the product conception, design and development phase should be seen as an opportunity than a regulatory and/or societal constraint. This is because the adoption of ecodesign principles generally fosters product innovation and reduces production costs (by reducing energy consumption, using natural resources and inputs, etc.), which enhances performance.

To meet these objectives of reducing environment impacts, communicating environmental information out to consumers and increasing performance, industry players need an in-depth picture of the environmental impacts of their products in order to work on reducing them and leverage the value of the ecodesign efforts engaged, and thus differentiate from any competitor products.

Conscious of this environmental and societal context, the oilcrop commodity chain wanted to provide vegetable oil producers and users with methods and tools for assessing commodities made from vegetable oils. The objective is to promote understanding of commodity chain impacts and analyze the room for progress at certain links for the purpose of design for environment and transparency for clients and consumers. Here we report the approaches implemented in the vegetable oil production sector and detail the environmental effect assessment tool ACéVOIL and its applications, as well as the difficulties tied to mobilizing value in the results of an environmental benefit assessment.

\section{What the 'vegetable oils' sector has done}

The French Grenelle roundtable process culminated in environmental legislation (the "Grenelle I Act" and "Grenelle II Act") that stipulated the right of consumers to have environmental information and prompted thinking on the idea of generalizing environmental labelling to fast-moving consumer goods. The governing ministry organized an initial experimental trial in 2011 to test the provisioning of environmental information on fast-moving consumer goods. The vegetable oils sector joined in this experiment by asking ITERG to provide support on the product environmental assessment strand (Badey et al., 2013). The ITERG started out by assessing the impact of rapeseed oil and sunflower oil production (based on data representative of French output from 2010, thus serving as baseline-standard values) under the ACéVOL project (FNCG and ITERG, 2012) sponsored by the key trade players (Terres Univia, FNCG [national fats industry federation], Lesieur, Saipol, Saint Hubert). In parallel to this work, ITERG employed the same methodology to study two oils in the Lesieur range ("fleur de colza" top-quality rapeseed oil and "cœur de tournesol" top-quality sunflower oil) produced through different value streams compared to their baseline-standard counterpart oils, and compared its process results on Lesieur against the 'baseline-standard' values for rapeseed oil and sunflower oil. This comparison enabled Lesieur to evaluate the benefits of its ecodesign initiatives and highlight areas where further improvements could be made (Badey et al., 2013).

Lessons learned from this experimentation included the need to harmonize the methods of environmental benefit assessment in order to ensure that consumers are given reliable environmental information that can be readily cross-compared between two products within the same product category (Ministry for Ecology, Energy and Sustainable Development, 2013). In response to this conclusion, ITERG proposed a "methodology guide for performing LCAs in the vegetable oils sector" published in 2012 and updated in 2017 (FNCG, ITERG and Terres Univia, 2017). The aim of this guide is to set sectorspecific procedural rules to be used for providing appropriately relevant environmental labelling information on vegetable oils.

A product and process assessment tool—ACéVOIL—was also made available to vegetable oil producers and users as a complement to this guide.

\section{What the ACéVOIL tool can do}

ACéVOIL is a tool that serves to produce LCAs for vegetable oils produced by oilseed processing and vegetable oil-based foods. It is an Excel spreadsheet that comes with a user guide. It is compliant with ISO 14040:2006 and ISO 14044:2006 standard requirements, which specify the principles and framework and the requirements for conducting and communicating on life cycle assessments. 
Table 1. Stratification of the lifecycle sub-stage impacts for the production of one tonne of refined sunflower oil.

\begin{tabular}{|c|c|c|c|c|}
\hline Lifecycle stages & $\begin{array}{l}\text { GHG emissions } \\
\left(\mathrm{kg} \text { eq. } \mathrm{CO}_{2}\right)\end{array}$ & $\begin{array}{l}\text { Net water } \\
\text { consumption (L) }\end{array}$ & $\begin{array}{l}\text { Eutrophication } \\
(\mathrm{kg} \text { eq. } \mathrm{N})\end{array}$ & $\begin{array}{l}\text { Ecotoxicity } \\
\text { (CTUe) }\end{array}$ \\
\hline Crop farming & $7.38 \mathrm{E}+02$ & $1.57 \mathrm{E}+04$ & $1.56 \mathrm{E}+01$ & $1.03 \mathrm{E}+04$ \\
\hline Crushing & $7.26 \mathrm{E}+01$ & $7.71 \mathrm{E}+02$ & $5.87 \mathrm{E}-03$ & $1.82 \mathrm{E}+02$ \\
\hline Refining & $8.62 \mathrm{E}+01$ & $9.80 \mathrm{E}+02$ & $7.36 \mathrm{E}-03$ & $2.77 \mathrm{E}+02$ \\
\hline $\begin{array}{l}\text { Transporting oilseed from } \\
\text { field to crushing site }\end{array}$ & $8.36 \mathrm{E}+01$ & $1.43 \mathrm{E}+02$ & $2.96 \mathrm{E}-02$ & $5.79 \mathrm{E}+02$ \\
\hline Total & $1.05 E+03$ & $1.77 \mathrm{E}+04$ & $1.57 \mathbf{E}+01$ & $1.17 E+04$ \\
\hline
\end{tabular}

As the oils produced can be either containered for use directly by the end-consumer or incorporated into other food products (margarine, biscuits, formulated foods, ready-made meals, etc.), the tool is designed to be applied for assessing the environmental impacts of vegetable oils produced by oilseed processing (sunflower, rapeseed, soy, linseed) and vegetable oil-based foods. The scope encompasses extracted oils, pressed oils and virgin oils produced through the processing of oilseed crops. The tool is French-sector-specific. It has been critically reviewed by an independent panel of reviewers, and can now be downloaded from the ITERG website.

The environmental impact indicators that ACéVOIL can model for assessment are those relating to GHG emissions, net water consumption, eutrophication and ecotoxicity. The process of choosing the environmental indicators and the associated calculation methods is set out in the "methodology guide for performing LCAs in the vegetable oils sector" (FNCG, ITERG and Terres Univia, 2017).

The tool is composed of two files. The first file is used to calculate environmental information for refined oils, from oilseed crop production through to shipment out from the refining-plant site, integrating:

- the impact of crop farming;

- the impact of dehulling (where appropriate);

- the impact of crushing;

- the impact of refining;

- the impact of intermediate site-to-site transport (from field to crushing plant and from crushing plant to refining plant).

This first file also proposes a comparison that benchmarks the results calculated against baseline-standard results for rapeseed and sunflower oils representative of French output (Badey et al., 2013). The baseline reference values are built to the same methodology principles and procedure as those used for the tool, which thus validates the comparisons effectuated.

Table 1 and figure 1 give an illustrative example of the result output obtained for the production of one tonne of refined sunflower oil. The input data used to obtain these results is the input data for the previously-studied baselinestandard sunflower oil (Badey et al., 2013). This output charts the aggregate all-lifecycle results. Figure 2 gives results for a specific sub-stage in the product lifecycle (refining), which do not account for the results of other lifecycle substages studied.
The second file is used to calculate environmental information for pre-packaged vegetable oil-based foods (running from bottled vegetable oil to mayonnaise), from shipment of the ingredients out from the production site through to delivery of the final product to the client's warehouse. This file is used to model:

- the bottling of a vegetable oil leaving the refining facility, or;

- a blend of several refined oils and its packaging, or;

- the formulation of a vegetable oil-based food and its packing.

This second file will therefore focus in on the phases involving:

- transport of ingredients (oil or others) up to the formulation/packing site;

- manufacture, transport and end-of-life disposal of packaging;

- packing (the process water and energy used);

- transport of finished product.

The results are expressed in units of the commodity product mass (per tonne of refined oil, for example).

Here, like all scientific results, the results obtained using ACéVOIL carry a range of uncertainty, which is linked, among other factors, to LCA methodology. The results obtained remain estimates of potential impacts and, as such, are to be handled with caution. Caution is especially warranted where there is a narrow gap between two results, as the gap may be non-significant.

This tool can serve users for several objectives:

- ecodesign;

- environmental performance information/labelling for clients/consumers.

\section{Using ACéVOIL to evaluate the value benefit of ecodesign initiatives}

Environmental product optimization has become a strategic challenge for businesses. It is equally a source of economic opportunities, as efforts to cut pollution tend to stimulate 


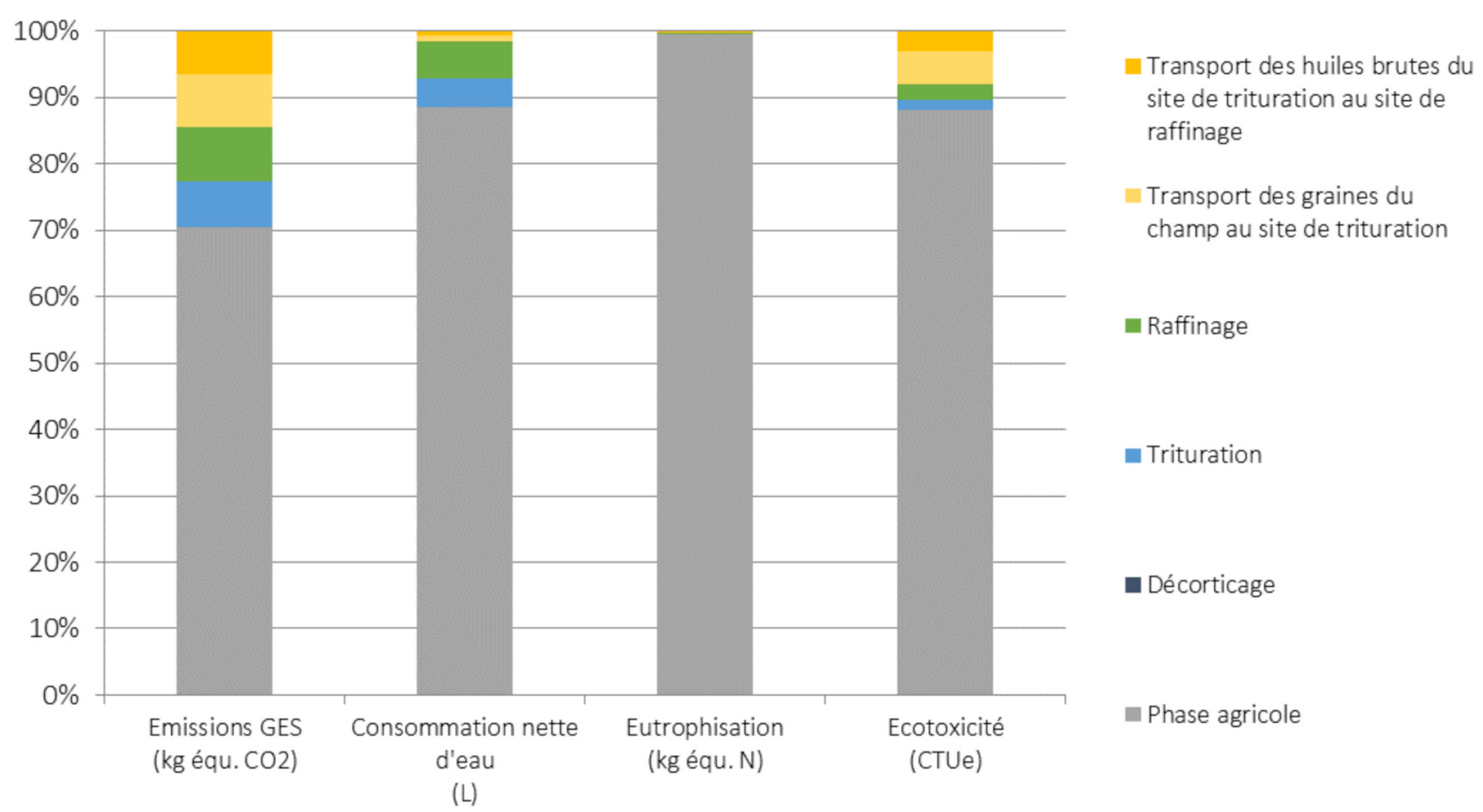

Fig. 1. Stratification of impacts for the production of one tonne of refined sunflower oil.

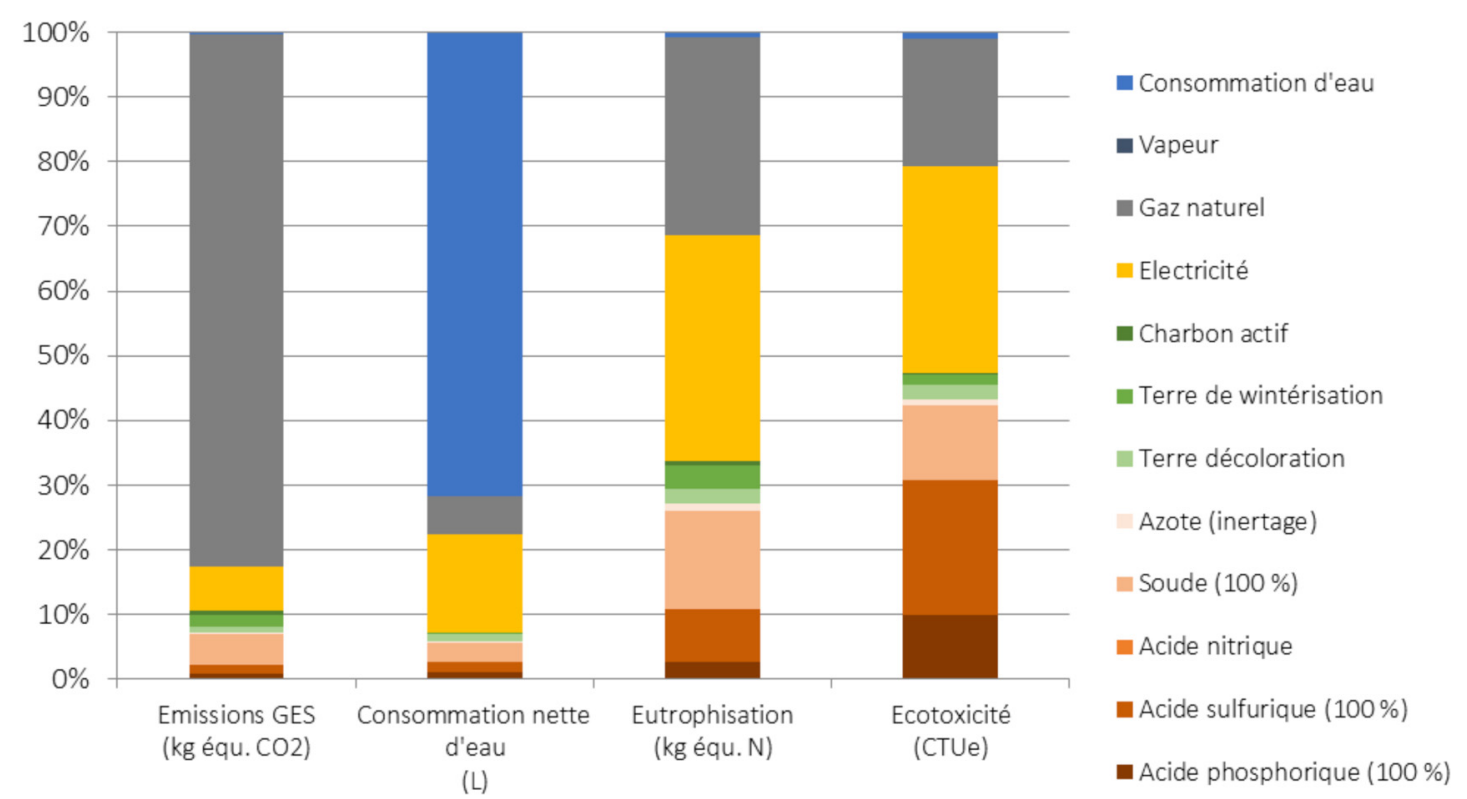

Fig. 2. Stratification of refining-stage impacts for the production of one tonne of refined oil.

innovation, reduce the amount of energy and materials used, and thereby increase productivity (Boiral, 2005).

That said, it is vital to first ensure that an ecodesign initiative implemented is actually environmentally virtuous. This makes it necessary to estimate the knock-on effects of an ecodesign initiative on the whole product lifecycle (a reduction in input energy consumption, for instance, can lead to a drop in output oil yield) and evaluate its repercussions in terms of environmental impact. It is important to ensure that there is no transfer of pollution between two categories of environmental impact and between two stages of the product lifecycle under study.

ACéVOIL is able to assess the environmental impacts of the initial situation and the situation including the as-designed ecodesign initiative, and thereby calculate the scale of the benefits gained by introducing the ecodesign initiative. It can serve to focus in on each sub-stage of the product lifecycle under study and get an aggregate all-lifecycle result. 


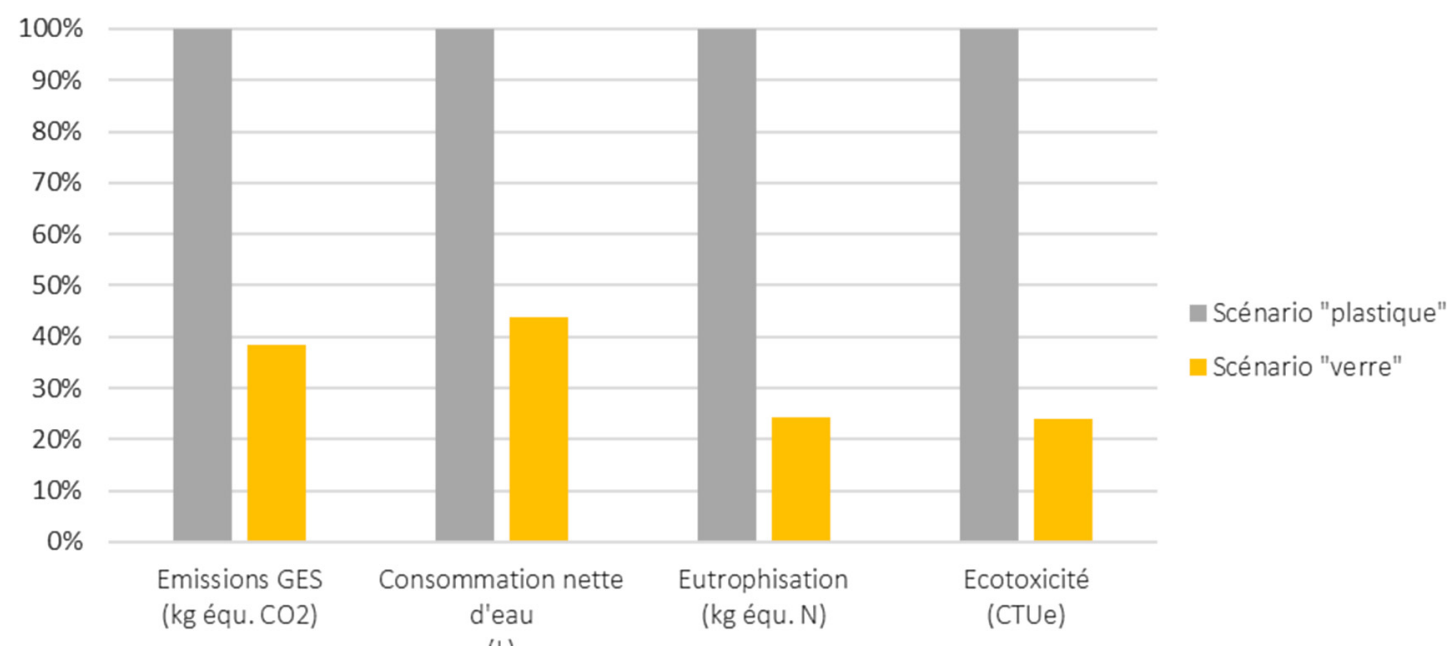

Fig. 3. Comparison of the two packaging scenarios for the "manufacture and end-of-life disposal of primary packaging materials" lifecycle step ratioed to $1 \mathrm{~kg}$ of bottled-oil.

To illustrate this application in an ecodesign scenario, take the fictive example of making a change in the material used to bottle-pack an oil. Imagine a company wants to switch from its regular plastic bottle to a glass bottle. Glass comes with valuable 'environmental' credentials due to the fact that the firmly established glass recycling sector in France enables a high rate of end-of-life recycling doubled with a promising rate of recyclate content. However, it also carries the disadvantage of being a heavier and bulkier material plastic, i.e. the packaging system required to container-pack $1 \mathrm{~kg}$ of oil will be heavier, which can be expected to add to transport-phase consumption. The ACéVOIL tool is used to model the plastic scenario, which assesses the environmental impacts of using a plastic bottle to container-pack $1 \mathrm{~kg}$ of oil, and the glass scenario, which assesses the environmental impacts of using a glass bottle to container-pack $1 \mathrm{~kg}$ of oil. The differences between the two scenarios read as follows:

- the weight of glass required to container-pack $1 \mathrm{~kg}$ of oil is around $30 \%$ higher than the weight of plastic required for the same functional usage;

- bottles-per-carton and bottles-per-pallet are lower (the glass scenario counts 8 fewer bottles-per-carton), which affects the amount of carton and pallet required, and the weight carried per truck;

- the glass bottle contains $10 \%$ recyclate material whereas the plastic bottle is made of $100 \%$ virgin material (zero recyclate content);

- the end-of-life recycling rate is $52 \%$ for plastic, whereas glass posts $74 \%$.

All the other parameters (distance covered in transport, process energy input for packing, production of co-ingredients, etc.) are identical between the two scenarios studied.

The results for the "production and end-of-life disposal of primary packaging material" stage of the lifecycle show a significant reduction in potential environmental impacts of 55$76 \%$ (depending on the indicators factored in) for the glass scenario (Fig. 3). However, the impact reduction found for the whole oil product lifecycle (including production of the oil and transport of the oil bottles) pans out much narrower (Fig. 4), at just $0-6 \%$. The aggregate all-lifecycle gap between these two scenarios is ultimately not insignificant. The narrowing of this gap is explained by the greater impact of transporting the oil under the glass scenario (which increased the impacts by around 3\%) and by the big factor weight of oil production on the product's all-lifecycle impacts.

Note that if the glass scenario had included a greater loss of oil during the container-packing process (as glass is more fragile than plastic), then this cross-comparison would have reached the opposite conclusion, with the plastic scenario emerging as more environmentally virtuous.

This example clearly shows the value of assessing the whole product lifecycle before validating the benefits of an ecodesign initiative.

\section{Communicating ACéVOIL results out to clients and consumers}

ACéVOIL results output can feasibly be released out to clients or consumers - but with conditions attached. Work conducted in France by the ADEME-chaired "environmental communication on mass market products" platform has not yet laid down hard requirements governing this kind of communication to the general public. The platform is currently looking into the requisite mechanisms for fact-checking information communicated to consumers, as groundwork to selecting a quickly readable and scientifically robust environmental label format. In the meantime, until government decides the direction for future environmental labelling in France, industry is advised to stick to the environmental communication requirements set out in the IS0 14040 LCA standards.

Where the results are intended to be disclosed outside the company, the user has a duty to ensure transparency on the results obtained by providing a lifecycle analysis report that details the methodology employed for collecting data and verifying the data inputs and outputs (results obtained). This report is to feature an annexe containing all the input data entered and the results output obtained. 


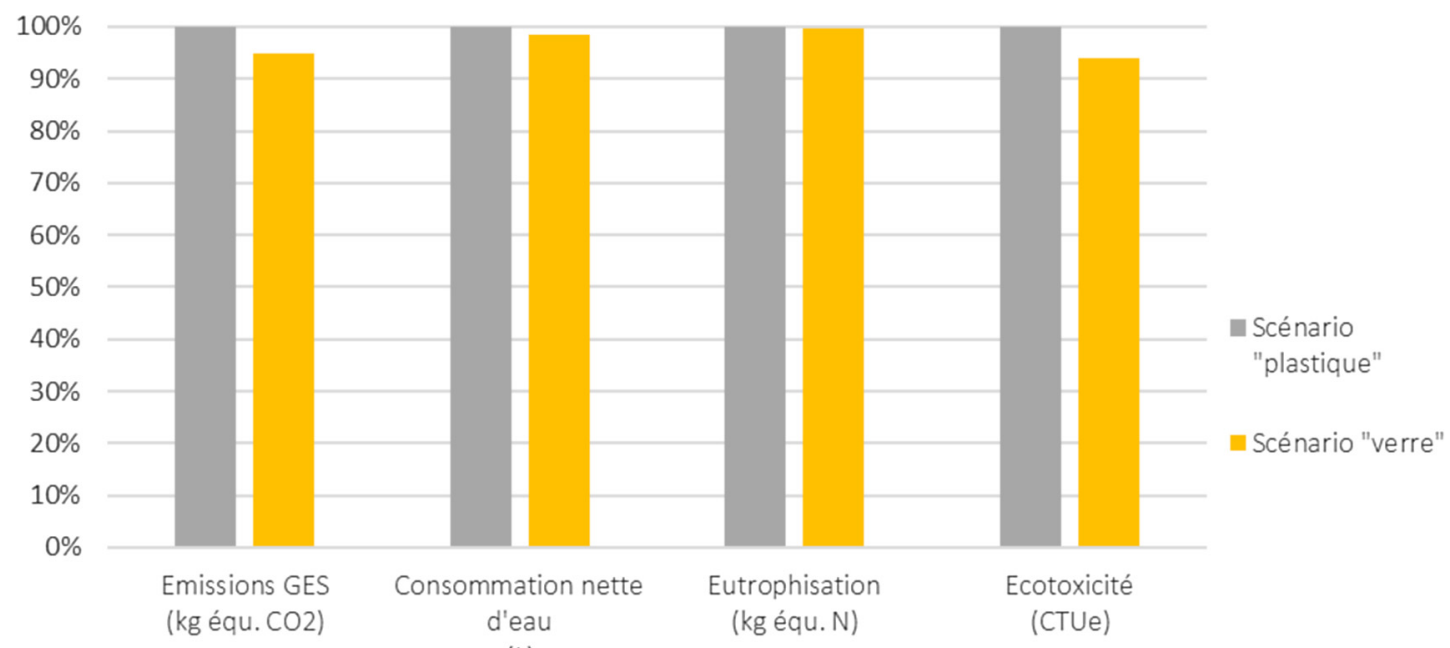

(L)

Fig. 4. Comparison of the two packaging scenarios for the entire end-to-end bottled-oil lifecycle ratioed to $1 \mathrm{~kg}$ of bottled-oil.

If the LCA results reporting is designed to be used in comparative assertions (which is generally the case with information disclosed to clients or consumers), then the ACéVOIL user shall submit the results obtained with its selfsourced data to critical independent review, as required under the ISO international standards. The fact that the tool has already undergone critical independent review, while not superseding this obligation, nevertheless makes it easier for ACéVOIL users to meet this requirement. The brief for the critical independent review of the results obtained by ACéVOIL user is to counterverify the data entered into the tool and the interpretation given to the results.

On top of this data transparency and critical review requirement, the communication of product environmental assessment carries other complications.

The execution of an LCA remains a scientific exercise, and the general public is ill-equipped to grasp all the ins and outs involved. The way the results are expressed (in kg eq. $\mathrm{CO}_{2}, \mathrm{~kg}$ $\mathrm{N}$, etc.) is already difficult for a public audience to relate to. The communication of LCA results is thus a tricky issue, which thus requires effort to repackage the information in a way that talks to the general public, but without compromising the quality of the science underpinning the results obtained. The simple fact that the ADEME-chaired platform has failed to come up with a consensus on the communication issue shows just how complex the exercise remains. The upshot is that environmental communication almost always focuses on the benefit of an environmentally-conscious initiative rather than on a product's global impact value.

Furthermore, recent studies have shown consumer distrust over corporate disclosure of environmental information. Effort is needed to improve transparency over the methods employed to assess environmental benefits in order to restore consumer confidence in the information delivered.

\section{Perspectives and outlook}

The environmental effect assessment tool ACéVOIL serves to assess ecodesign initiatives as-deployed or asdesigned over the whole end-to-end product lifecycle. The tool enables industry to check that initiatives engaged are actually environmentally virtuous and to quantify the aggregate environmental value benefits delivered. This makes it a fully-fledged decision support tool, enabling businesses to improve product environmental impact and productivity as a whole.

The ACéVOIL tool also meets the need for business to calculate the environmental impact of a product or process in order to differentiate from competitor products and communicate out to clients and/or consumers. However, information delivered to consumers has to be scientifically robust in terms of science yet readily understandable by the wider public, which hampers efforts to leverage the value of ecodesign initiatives with shoppers.

Note, however, that the tool is limited by the fact that it expresses results as a ratio of units of food product mass, which mechanically flaws attempts to compare two oils with different functions and/or properties. For instance, an oil with a heavier environmental impact may have more valuable nutritional qualities, thus justifying an impact gap (as it may be necessary to consume more of another oil to get the same nutritional benefits). Over the coming years, effort needs to be channeled into defining a functional unit that fully accounts for the product's function (including nutritional function).

There are several projects in the pipeline to upgrade the tool. The tool is being readied for a new release designed to focus on value-streams for non-food applications. The idea is to define a set of rules and propose a computational tool for quantifying the environmental impact of a bio-based product blended using vegetable oils or oil-mill co-products. The ultimate goal is gauge the impact of switching from petroleumsourced products to oil-mill-sourced products.

Another project tabled is to complete the environmental analysis delivered by the tool by integrating socio-economic aspects of sustainability. The tool is effectively exclusively concerned with the environmental impacts of producing pure oil and oil-based foods. Heightened consumer concern over the environmental sustainability of the food they eat should not eclipse the other two pillars in the triple bottom line, i.e. social sustainability and economic sustainability. Future research will 
need to focus towards a more integrated assessment of all three pillars.

\section{Supplementary Material}

French version.

The Supplementary Material is available at https://www.ocljournal.org/10.1051/ocl/2018005/olm.

Acknowledgements. The authors thank Terres Univia for funding support, and the project steering committee members who participated in this study for their contribution.

\section{References}

Badey L, Lahitte N, Flenet F, Bosque F. 2013. French environmental communication on sunflower and rapeseed oils based on life cycle assessment. OCL 20(4).

Boiral O. 2005. Concilier environnement et compétitivité, ou la quête de l'éco-efficience. Rev Fr Gestion 158(5): 163-186.
Ceci-Renaud N, Clément M, Tarayoun T. 2017. L'affichage environnemental pour une consommation plus verte. Essentiel, CGDD, January 2017.

FNCG and ITERG. 2012. ACéVOL - Analyse de Cycle de Vie pour les Oléagineux. Détermination de l'information environnementale des huiles de colza et de tournesol dites « de référence ». 2012 Report.

FNCG, ITERG and Terres Univia. 2017. Référentiel méthodologique pour la réalisation d'ACV dans le secteur des huiles végétales version 4.

ISO 14044:2006. Environmental Management - Life cycle assessment - Requirements and guidelines.

ISO 14040:2006. Environmental Management - Life cycle assessment - Principles and framework.

Ministère de l'écologie, du développement durable et de l'énergie. 2013. Affichage environnemental des produits de grande consommation, bilan au Parlement de l'expérimentation nationale. September 2013.

Pautard E. 2016. Opinions et pratiques environnementales des Français en 2015. Chiffres \& statistiques, CGDD 70, April 2016.

Rolland A. 2017. Qui est prêt à payer davantage pour un produit vert. Essentiel, CGDD, January 2017.

Cite this article as: Badey L, Bosque F. 2018. Product environmental assessment as vector of differentiation-ACéVOIL, a new tool for the vegetable oil sector. $O C L$ 25(2): D208. 